\title{
PENGARUH PRAKTIK KERJA INDUSTRI DAN PRESTASI BELAJAR MATA PELAJARAN PRODUKTIF TERHADAP KESIAPAN KERJA SISWA
}

\author{
Aditya wahyu ${ }^{1}$, Dwiki Muda Yulanto ${ }^{2}$, Sapitri Januariyansah ${ }^{3}$, Didik Rohmantoro ${ }^{4}$. \\ ${ }^{1}$ Fakultas Sains dan Teknologi, Universitas Ivet, Indonesia. \\ Email: adityawahyu@gmail.com \\ ${ }^{2}$ Pendidikan Teknik Otomotif, Fakultas Teknik, Universitas Negeri Medan, Indonesia. \\ ${ }^{3}$ Pendidikan Teknik Otomotif, Fakultas Teknik, Universitas Negeri Medan, Indonesia. \\ ${ }^{4}$ Fakultas Keguruan dan Ilmu Pendidikan, Universitas PGRI Yogyakarta, Indonesia.
}

\begin{abstract}
ABSTRAK
Sekolah Menengah Kejuruan merupakan lembaga pendidikan yang berorientasi pada pengembangan sumber daya manusia yang memiliki kompetensi dan siap kerja. Sekolah Menengah Kejuruan harus menyiapkan siswa yang berkompeten dan siap kerja. Salah satu caranya adalah melalui praktik kerja industri. Siswa harus memiliki ilmu pengetahuan dan kompetensi yang memadai. Kompetensi siswa dapat dilihat dari prestasi belajarnya. Penelitian ini bertujuan untuk mengetahui: (1) Pengaruh praktik kerja industri terhadap kesiapan kerja siswa; (2) Pengaruh prestasi belajar mata pelajaran produktif terhadap kesiapan kerja siswa; (3) Pengaruh praktik kerja industri dan prestasi belajar mata pelajaran produktif terhadap kesiapan kerja. Metode penelitian yang di gunakan adalah kuantitatif dan pendekatan yang digunakan adalah ex post facto. Populasi dalam penelitian ini adalah seluruh siswa XII TKR SMK Negeri 10 Semarang yang berjumlah 83 siswa. Sampel dalam penelitian ini berjumlah 69 siswa XII TKR SMK Negeri 10 Semarang, menggunakan proporsional random sampling. Pengumpulan data menggunakan angket dan dokumentasi. Hasil penelitian menunjukkan: (1) Praktik kerja industri berpengaruh terhadap kesiapan kerja siswa XII TKR SMK Negeri 10 Semarang; (2) Prestasi belajar mata pelajaran produktif berpengaruh terhadap kesiapan kerja siswa XII TKR SMK Negeri 10 Semarang; (3) Praktik kerja industri dan prestasi belajar mata pelajaran produktif berpengaruh terhadap kesiapan kerja siswa XII TKR SMK Negeri 10 Semarang.
\end{abstract}

Kata kunci: kesiapan kerja, praktik kerja industri, prestasi belajar, teknik otomotif. 


\title{
Journal of Automotive Technology Vocational Education
}

Volume 1, No 1, April 2020

Online: http://ojs.upy.ac.id/ojs/index.php/jatve

\begin{abstract}
Vocational High School is an educational institution oriented to the development of human resources who have the competency and are ready to work. Vocational High Schools must prepare competent and ready-to-work students. One way is through industrial work practices. Vocational students must have adequate knowledge and competence. Student competencies can be seen in their learning achievements. This study aims to determine: (1) The effect of industrial work practices on student work-readiness; (2) The effect of productive subject learning achievement on student work-readiness; (3) The effect of industrial work practices and the learning achievement of productive subjects on work readiness. The research method used is quantitative and the approach used is posted facto. The population in this study were all XII TKR students of SMK Negeri 10 Semarang, amounting to 83 students. The sample in this study amounted to 69 XII TKR students of SMK Negeri 10 Semarang, using proportional random sampling. Data collection uses questionnaires and documentation. The results showed: (1) Industrial work practices influence work readiness of XII TKR students of SMK Negeri 10 Semarang; (2) Learning achievement of productive subjects influences work readiness of XII TKR students of SMK Negeri 10 Semarang; (3) Industrial work practice and learning achievement of productive subjects influence work readiness of XII TKR students of SMK Negeri 10 Semarang.
\end{abstract}

Keywords: automotive engineering, industrial work practices, learning achievements, work readiness.

\section{PENDAHULUAN}

Menurut Undang-undang No.20/2003

pasal 15 tentang Sistem Pendidikan Nasional, pendidikan kejuruan merupakan pendidikan menengah yang mempersiapkan peserta didik terutama untuk bekerja dalam bidang tertentu. Sekolah Menengah Kejuruan (SMK) merupakan sekolah yang mempersiapkan peserta didiknya untuk menjadi sumber daya manusia yang memiliki pengetahuan dan keterampilan, sehingga diharapkan setelah selesai akan siap untuk bekerja. Pendidikan di SMK bertujuan untuk menyiapkan peserta didik agar menjadi manusia yang produktif, mampu bekerja mandiri, mengisi lowongan pekerjaan yang ada di dunia usaha dan dunia industri sebagai tenaga kerja tingkat menengah sesuai dengan kompetensi dalam program keahlian yang dipilihnya (Rohmantoro, 2018). Selain itu, pendidikan kejuruan juga bertujuan untuk mengembangkan keterampilan, kemampuan, pemahaman, sikap, kebiasaan kerja, dan pengetahuan bagi siswa guna memenuhi dan mengembangkan keterampilan kerja agar mampu menjadi pekerja yang betul-betul berguna dan produktif.

Penerapan Pendidikan Sistem Ganda dimaksudkan agar SMK bekerja sama dengan dunia usaha atau dunia industri dan instansi terkait. Menurut Made , (1996:2122) Praktik industri adalah kegiatan yang dilakukan oleh peserta didik berupa praktik langsung pada dunia kerja yang nyata. Praktik industri merupakan bentuk belajar yang paling bermanfaat bagi pembentukan keterampilan peserta didik. Karena itulah maka kegiatan ini paling banyak dilaksanakan, khususnya pada negara-negara yang pendidikan kejuruan nya telah maju. Tanpa melakukan kegiatan praktik industri secara sistematis jelas suatu lembaga 
pendidikan kejuruan tidak akan bisa membekali lulusannya dengan kemampuan kerja yang optimal (Mareta, Metta. 2009) . Kerja sama tersebut diharapkan dapat menghasilkan siswa yang memiliki kompetensi sesuai dengan bidang keahlian yang dipilihnya serta memiliki pengalaman yang dapat dijadikan sebagai bekal kesiapan untuk terjun ke dunia kerja.

Kesiapan kerja adalah keseluruhan kondisi seseorang yang membuatnya siap untuk memberi respons/ jawaban di dalam cara tertentu terhadap suatu situasi (Slameto, 2013). Penyesuaian kondisi pada suatu saat akan berpengaruh pada atau kecenderungan untuk memberi respons. Kondisi ini mencakup setidak-tidaknya 3 aspek yaitu, (1) Kondisi fisik, mental dan emosional, (2) Kebutuhan-kebutuhan, motif dan tujuan, (3) Keterampilan, pengetahuan dan pengertian lain yang telah dipelajari. Kesiapan kerja di pengaruhi oleh faktor-faktor dari dalam (faktor intern) dan faktor dari luar (faktor ekstern). Faktor intern meliputi : kecerdasan, keterampilan, kecakapan, bakat, kemampuan, minat, motivasi, kesehatan, kebutuhan psikologis, kepribadian, cita-cita, dan tujuan dalam bekerja. Faktor ekstern meliputi lingkungan keluarga, lingkungan dunia kerja, rekan bekerja, hubungan dengan pimpinan, dan gaji.

Kesiapan seseorang dapat dibentuk melalui pengalaman yang diperolehnya. Pengalaman yang dimaksud adalah pengetahuan dan keterampilan yang diperoleh sebagai hasil dari suatu perbuatan atau pekerjaan yang telah dilakukan (Rohmantoro, 2018). Untuk menyiapkan tenaga kerja yang memiliki pengetahuan dan keterampilan, maka SMK menjalin kerja sama dengan dunia usaha maupun dunia industri. Peserta didik di terjunkan ke dunia kerja diharapkan mampu menyerap ilmu dan pengetahuan tentang dunia kerja sehingga diharapkan setelah lulus dari pendidikan sekolah menengah kejuruan siswa sudah memiliki kesiapan kerja yang akan memudahkan siswa dalam memperoleh pekerjaan. SMK yang berbasis manajemen, pelatihan industri ini disebut dengan Praktik Kerja Industri (Prakerin) yang merupakan bentuk dari kebijakan Pendidikan Sistem Ganda.

SMK Negeri 10 Semarang memiliki beberapa kompetensi keahlian, diantaranya adalah Teknik Kendaraan Ringan, Teknik Sepeda Motor, Pembuatan Dan Perbaikan Bodi Kapal, Pemasangan Dan Perbaikan Mesin Kapal, Nautika Kapal Niaga, Rekayasa Perangkat Lunak, dan Teknik Pengelasan.

Kompetensi keahlian Teknik Kendaraan Ringan merupakan salah satu kompetensi keahlian unggulan di SMK Negeri 10 semarang. Siswa pada kompetensi keahlian teknik kendaraan ringan diarahkan untuk menjadi lulusan yang siap kerja secara professional di bidang perawatan dan produksi bidang kendaraan ringan.

Berdasarkan hasil observasi yang dilakukan dengan melakukan wawancara pada siswa kelas XII TKR SMK Negeri 10 Semarang, di peroleh kesimpulan bahwa siswa belum sepenuhnya untuk menghadapi dunia kerja, utamanya untuk bekerja di bengkel perbaikan kendaraan ringan, mereka memilih bekerja sedapatnya yang penting bekerja. Selain itu penyampaian informasi tentang lowongan pekerjaan juga kurang maksimal. informasi lowongan pekerjaan 
yang disampaikan oleh lembaga bursa kerja khusus hanya melalui media cetak yang di tempel di papan informasi sekolah, sehingga informasi tersebut tidak dapat tersampaikan dengan baik ke lulusan. Seharusnya bursa kerja khusus yang ada di sekolah menyampaikan informasi lowongan pekerjaan melalui Information And Communication Technologies (ICT). Melalui pemanfaatan kemajuan ICT, SMS dan email merupakan kemajuan teknologi ICT yang dapat di gunakan untuk menyampaikan informasi dengan cepat dan tepat sasaran. Informasi yang di sampaikan secara cepat dan tepat akan membantu mempermudah lulusan SMK memperoleh pekerjaan (Rohmantoro, Meldianto, \& Januariyansah, 2017).

Melihat fenomena tersebut perlu adanya kebijakan dalam hal peningkatan mutu lulusan yang siap memasuki dunia kerja sesuai dengan tujuan pendidikan menengah kejuruan. Berdasarkan data tersebut dapat disimpulkan bahwa masih banyak siswa yang belum siap menghadapi tantangan dunia kerja di bidang teknik kendaraan ringan, padahal sekolah sudah mengadakan program Praktik Kerja Industri dan juga membekali siswa dengan mata pelajaran produktif. Dari data tersebut penulis melalukan penelitian dengan judul "Pengaruh Program Praktik Kerja Industri dan Prestasi Belajar Mata Pelajaran Produktif Terhadap Kesiapan Kerja Siswa Kelas XII TKR SMK Negeri 10 Semarang”.

\section{METODE PENELITIAN}

Penelitian ini di lakukan di SMK Negeri 10 Semarang, yang beralamat di Jalan waktu Penelitian dilakukan selama 3 bulan.
Penelitian ini merupakan penelitian kuantitatif yang menggunakan pendekatan $e x$ post facto, dimana melakukan kajian mengenai pengaruh variabel bebas praktik kerja industri $\left(\mathrm{X}_{1}\right)$, dan prestasi belajar mata pelajaran produktif $\left(\mathrm{X}_{2}\right)$ terhadap variabel terikat kesiapan kerja $(\mathrm{Y})$.

Populasi dalam penelitian ini adalah seluruh siswa kelas XII TKR SMK Negeri 10 Semarang yang berjumlah 83 siswa. Sampel dalam penelitian ini berjumlah 69 siswa XII TKR SMK Negeri 10 Semarang, menggunakan proporsional random sampling. Pengumpulan data menggunakan angket dan dokumentasi.

\section{HASIL DAN PEMBAHASAN}

\section{A. Hasil analisis Uji T.}

Analisis Uji-T digunakan untuk menguji signifikasi pengaruh variabel bebas (praktek kerja industri dan prestasi mata pelajaran produktif) secara parsial terhadap variabel terikat (kesiapan kerja). Pengujian ini dilakukan dengan program SPSS.V.20.0.

Tabel 1. Uji-T Parsial

\begin{tabular}{lll}
\hline No & Variabel & Sig. \\
\hline 1 & Praktik Kerja Industri & .008 \\
2 & Prestasi Belajar Mata & .007 \\
& Pelajaran Produktif & \\
\hline
\end{tabular}

1. Uji Hipotesis Pertama (Praktik Kerja Industri $\left(\mathrm{X}_{1}\right)$ terhadap Kesiapan Kerja (Y))

Dalam pengujian hipotesis praktik kerja industri secara parsial menggunakan dua hipotesis yaitu $\mathrm{H}_{1}$ : Ada pengaruh variable praktik kerja industri terhadap kesiapan kerja dan $\mathrm{H}_{0}$ : Tidak ada pengaruh variable praktik kerja industri terhadap 
kesiapan kerja dengan tingkat signifikan $\alpha=$ $5 \%(0,05)$, penolakan $\mathrm{H}_{0}$ dilakukan jika nilai $\mathrm{P}_{\text {value }}<\alpha$. Berdasarkan pengujian statistik menggunakan SPSS.V.20.0, diketahui nilai $\mathrm{P}_{\text {value }}$ (sig) sebesar 0,008 sehingga diperoleh $\mathrm{P}_{\text {value }}(0,008)<\alpha(0,05)$, maka $\mathrm{H}_{0}$ ditolak. Jadi dapat di simpulkan bahwa, ada pengaruh variable praktek kerja industri terhadap kesiapan kerja.

2. Uji Hipotesis Kedua (Prestasi Belajar Mata Pelajaran Produktif $\left(\mathrm{X}_{2}\right)$ terhadap Kesiapan Kerja (Y)

Dalam pengujian hipotesis prestasi belajar mata pelajaran produktif secara parsial menggunakan dua hipotesis yaitu $\mathrm{H}_{1}$ : Ada pengaruh variable prestasi belajar mata pelajaran produktif terhadap kesiapan kerja dan $\mathrm{H}_{0}$ : Tidak ada pengaruh variable prestasi belajar mata pelajaran produktif terhadap kesiapan kerja dengan tingkat signifikan $\alpha=$ $5 \%(0,05)$, penolakan $\mathrm{H}_{0}$ dilakukan jika nilai $\mathrm{P}_{\text {value }}<\alpha$. Berdasarkan pengujian statistik menggunakan SPSS.V.20.0, diketahui nilai $\mathrm{P}_{\text {value }}$ (sig) sebesar 0,007 sehingga di peroleh $\mathrm{P}_{\text {value }}(0,007)<\alpha(0,05)$, maka $\mathrm{H}_{0}$ ditolak, Jadi dapat disimpulkan bahwa, ada pengaruh variable prestasi belajar mata pelajaran produktif terhadap kesiapan kerja.

\section{B. Hasil analisis Uji F}

Dalam pengujian hipotesis praktik kerja industri dan prestasi belajar mata pelajaran produktif secara $\mathrm{F}$ (simultan) menggunakan dua hipotesis yaitu $\mathrm{H}_{1}$ : Ada pengaruh variable praktik kerja industri dan prestasi belajar mata pelajaran produktif terhadap kesiapan kerja dan $\mathrm{H}_{0}$ : Tidak ada pengaruh variable praktik kerja industri dan prestasi belajar mata pelajaran produktif terhadap kesiapan kerja, dengan tingkat signifikan $\alpha=5 \%(0,05)$, penolakan $\mathrm{H}_{0}$ dilakukan jika nilai $\mathrm{P}_{\text {value }}<\alpha$.

Tabel 2. Uji-F Simultan

\begin{tabular}{lll}
\hline Model & F & Sig. \\
\hline Regression & 92.796 & .004 \\
\hline
\end{tabular}

Berdasarkan pengujian Statistik menggunakan SPSS.V.20.0, diketahui nilai $\mathrm{P}_{\text {value }}$ (sig) sebesar 0,004, sehingga diperoleh $\mathrm{P}_{\text {value }}(0,004)<\alpha(0,05)$, maka $\mathrm{H}_{0}$ ditolak. Jadi dapat disimpulkan bahwa, ada pengaruh variable praktik kerja industri dan prestasi belajar mata pelajaran produktif terhadap kesiapan kerja.

\section{Koefisien Determinasi $X_{1}$ Terhadap $Y$}

Berikut adalah hasil uji koefisien determinasi menggunakan SPSS v.20.0.

Tabel 3. Hasil Uji Koefisien Determinasi $\mathrm{X}_{1}$

\begin{tabular}{ll}
\multicolumn{2}{c}{ terhadap Y } \\
\hline Variable & Value \\
\hline $\begin{array}{l}\text { Correlation coefficient (R) } \\
\text { Coefficient of }\end{array}$ & 0,852 \\
$\begin{array}{l}\text { Determination (R Square) } \\
\text { Significance level }\end{array}$ & 0,726 \\
\hline
\end{tabular}

Berdasarkan Tabel 3, nilai $\mathrm{R}$ square adalah sebesar 0,726 atau sama dengan $72,6 \%$. Angka tersebut berarti variable praktik kerja industri $\left(\mathrm{X}_{1}\right)$ berpengaruh terhadap kesiapan kerja (Y) sebesar $72,6 \%$. Sedangkan sisanya $(100 \%-72,6 \%=27,4 \%)$ dipengaruhi oleh variable lain.

\section{Koefisien Determinasi $X_{2}$ Terhadap $Y$}


Berikut adalah hasil uji koefisien determinasi menggunakan SPSS v.20.0.

Tabel 4. Tabel Uji Koefisien Determinasi $\mathrm{X}_{2}$

\begin{tabular}{ll}
\multicolumn{2}{c}{ Terhadap Y } \\
\hline Variable & Value \\
\hline Correlation coefficient (R) & 0,014 \\
Coefficient of & 0,001 \\
Determination (R Square) & 0,909 \\
Significance level & \\
\hline
\end{tabular}

Berdasarkan Tabel 4, nilai $\mathrm{R}$ square adalah sebesar 0,001 atau sama dengan 0,1\%. Angka tersebut berarti variable prestasi belajar mata pelajaran produktif $\left(\mathrm{X}_{2}\right)$ berpengaruh terhadap kesiapan kerja (Y) sebesar $0,1 \%$. Sedangkan sisanya (100\%$0,1 \%=99,9 \%$ ) dipengaruhi oleh variable lain.

\section{E. Koefisien Determinasi $X_{1}$ dan $X_{2}$ Terhadap Y}

Berikut adalah hasil uji koefisien determinasi menggunakan SPSS v.20.0.

Tabel 5. Tabel Uji Koefisien Determinasi $X_{1}$

\begin{tabular}{ll}
\multicolumn{2}{c}{ dan $\mathrm{X}_{2}$ Terhadap $\mathrm{Y}$} \\
\hline Variable & Value \\
\hline Correlation coefficient (R) & 0,859 \\
Coefficient of & 0,738 \\
$\begin{array}{l}\text { Determination (R Square) } \\
\text { Significance level }\end{array}$ & 0,001
\end{tabular}

Berdasarkan Tabel 5, nilai $\mathrm{R}$ square adalah sebesar 0,738 atau sama dengan $73,8 \%$. Angka tersebut berarti variable praktik kerja industri $\left(\mathrm{X}_{1}\right)$ dan variable prestasi belajar mata pelajaran produktif $\left(\mathrm{X}_{2}\right)$ berpengaruh terhadap kesiapan kerja (Y) sebesar $73,8 \%$. Sedangkan sisanya (100\%$73,8 \%=26,2 \%$ ) dipengaruhi oleh variable lain

\section{PENUTUP}

\section{A. Kesimpulan}

Dari hasil analisis dan pembahasan dapat disimpulkan sebagai berikut: (1) Praktik kerja industri berpengaruh terhadap kesiapan kerja siswa XII TKR SMK Negeri 10 Semarang. Praktik kerja industri memberikan pengaruh terhadap kesiapan kerja siswa XII TKR SMK Negeri 10 Semarang sebesar 72,6\%, (2) Prestasi belajar mata pelajaran produktif berpengaruh terhadap kesiapan kerja siswa XII TKR SMK Negeri 10 Semarang. Prestasi belajar mata pelajaran produktif memberikan pengaruh terhadap kesiapan kerja siswa XII TKR SMK Negeri 10 Semarang sebesar $0,1 \%$, (3) Praktik kerja industri dan prestasi belajar mata pelajaran produktif berpengaruh terhadap kesiapan kerja siswa XII TKR SMK Negeri 10 Semarang. Praktik kerja industri dan prestasi belajar mata pelajaran produktif memberikan pengaruh terhadap kesiapan kerja siswa XII TKR SMK Negeri 10 Semarang sebesar $73,8 \%$.

\section{DAFTAR PUSTAKA}

Mareta, M. (2009). Pengaruh Implememntasi Pendidikan Sistem Ganda (Psg) Terhadap Kesiapan Menghadapi Dunia Kerja Siswa Kelas Xii Program Keahlian Akuntansi Smk Diponegoro Salatiga Tahun 2008/2009. Skripsi. Universitas Negeri Semarang. Semarang.

Rohmantoro, D. (2018). Pengaruh Praktik Kerja Industri, Budaya Kerja 5s, Dan Motivasi Kerja Terhadap Kesiapan Kerja Siswa Pada Smk Binaan Pt. Astra Daihatsu Motor Di Diy. Universitas Negeri Yogyakarta. 
Journal of Automotive Technology Vocational Education

Vol. 01, No. 1, April 2020

Rohmantoro, D., Meldianto, E., \& Januariyansah, S. (2017). Information

And Communication Technologies Pada Bursa Khusus Kerja Di Sekolah Menengah Kejuruan. In J. A. Saiful, N. A. Rahayu, \& I. Fatwa (Eds.), "21st Century Trends And Innovations In Education Endeavor: Integrating 21st Century Skills Into Practice. Yogyakarta: UNY Press.

Slameto. (2003). Belajar Dan Faktor-Faktor

Yang Mempengaruhinya. Jakarta: Rineka Cipta.

UU No. 20/2003 Tentang Sistem Pendidikan Nasional 